\title{
ELECTRON INTER-VALLEY TRANSFER DYNAMICS IN GERMANIUM STUDIED BY THE OPTICAL PUMP - TERAHERTZ PROBE TECHNIQUE
}

\author{
A. Urbanowicz ${ }^{\text {a }}$, R. Adomavičius ${ }^{\text {a }}$, A. Krotkus ${ }^{a}$, and V.L. Malevich ${ }^{\text {b }}$ \\ ${ }^{a}$ Semiconductor Physics Institute, A. Goštauto 11, LT-01108 Vilnius, Lithuania \\ E-mail: aurban@pfi.lt \\ ${ }^{\mathrm{b}}$ Institute of Physics, National Academy of Sciences of Belarus, F. Skaryna Ave. 68, 220072, Minsk, Republic of Belarus
}

Received 26 October 2005

\begin{abstract}
The electron dynamics in germanium was studied both experimentally and theoretically. Visible pump - THz probe technique was used for experimental observation of the electron inter-valley transfer dynamics in that material; measurement results were compared with the numerical Monte Carlo simulation. The value of the deformation potential for electron scattering between nonequivalent $\mathrm{L}$ and $\Delta$ valleys was determined from this comparison and the possible use of Ge crystals in ultrafast optoelectronics was discussed.
\end{abstract}

Keywords: germanium, optical pump terahertz probe

PACS: $42.65 . \operatorname{Re}, 72.30 .+\mathrm{q}, 78.47 .+\mathrm{p}$

\section{Introduction}

The advent of lasers generating femtosecond pulses has resulted in a wealth of useful information concerning the electron dynamics in semiconductors. Various pump-and-probe type optical measurement techniques allowed to measure nonequilibrium carrier lifetimes in semiconductors down to the values smaller than 1 ps [1-3] and to study the electron intra- and interband redistribution on the same and even shorter time scale [4]. For the latter experiment, the most appropriate experimental technique seems to be the visible pump - terahertz (THz) probe measurement [5], because it supports the direct monitoring of the most mobile species of current carriers in the material due to induced free-carrier absorption at $\mathrm{THz}$ wavelengths. Recently, this technique has been successfully employed in, e.g., studying the electron scattering between the main and subsidiary conduction band valleys in GaAs [6].

In the present work, the electron dynamics in germanium - a classical semiconductor material that has a complicated many-valley conduction band structure is studied both experimentally and theoretically. Four lowest lying conduction band valleys are situated at $\mathrm{L}$ points of the Brillouin zone, the central $\Gamma$ valley is lying at $0.12 \mathrm{eV}$ higher energy, and at $0.18 \mathrm{eV}$ above the
L valleys six additional $\Delta$ valleys can be found. These details of the band structure, the intensity of electron redistribution between different groups of the conduction band valleys, are becoming increasingly important for material engineering of Si-Ge alloys. Visible pump $\mathrm{THz}$ probe technique was used for experimental observation of the electron inter-valley redistribution in this material; measurement results were compared with the numerical Monte Carlo simulation. The value of the deformation potential for the electron scattering between nonequivalent $\mathrm{L}$ and $\Delta$ valleys was determined from this comparison and possible use of Ge crystals in ultrafast optoelectronics was discussed.

\section{Experiment}

In the experiments, both the $\mathrm{THz}$ radiation pulse emitter and the detector were made as dipole antennae on low-temperature MBE grown GaAs layer and were activated by parts of a Ti:sapphire laser beam (of $150 \mathrm{fs}$ duration, $76 \mathrm{MHz}$ repetition rate, and $810 \mathrm{~nm}$ central wavelength). The third part of the same laser beam was used for the photoexcitation of the samples. The samples of $n$ - and $p$-type Ge with the highest resistivity available $(\rho=10 \Omega \cdot \mathrm{cm})$ were placed right behind the metallic aperture with the diameter of $300 \mu \mathrm{m}$; both 


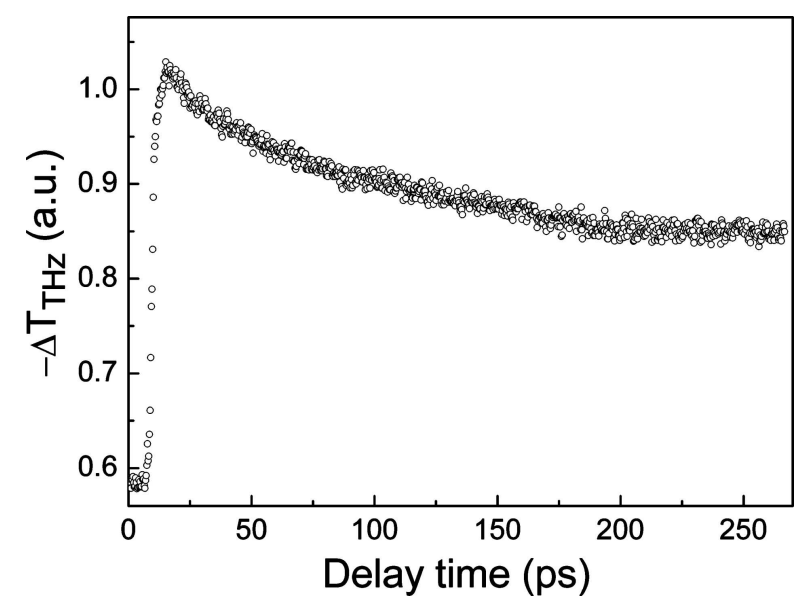

Fig. 1. Temporal dynamics of optical pump induced transmittance in $p$-type $\mathrm{Ge}$ sample at $\mathrm{THz}$ frequencies.

optical pump and $\mathrm{THz}$ probe beams were made to overlap at this aperture. The dependence of the THz transient signal at its maximum was measured at different delays of the optical pump pulse. The temporal resolution of this experiment was determined by the response of the detector measuring $\mathrm{THz}$ transients and was approximately equal to $500 \mathrm{fs}$.

The photoexcited electron dynamics was studied by an ensemble Monte Carlo simulation. In our calculation, Herring and Vogt transformation [7,8] was used for the electrons in the L valleys, turning the ellipsoidal constant energy surfaces of those valleys spherical. The contribution of $\Delta$-electrons to the $\mathrm{THz}$ transient generation is rather small due to their low mobility, therefore a simplified, spherically symmetric model of the $\Delta$-valleys has been assumed in the calculation. In the valence band of germanium only the heavy holes with an isotropic dispersion law are taken into account. The intra-valley scattering of electrons and holes in Ge are assumed to interact with acoustic and optical phonons. Deformation potential type interaction was taken into account; electrons in $\Gamma$ and $\Delta$ valleys had interacted only with the acoustic phonons. Intense inter-valley scattering, which results in the transfers of electrons between equivalent and non-equivalent valleys of the conduction band, has also been taken into account in our Monte Carlo procedure similarly as it has been done in [8].

\section{Results and discussion}

Figure 1 shows the results of the visible pump $-\mathrm{THz}$ probe measurement. The data presented in this figure correspond to $p$-type material; similar results have been obtained also on $n$-type Ge. Transient absorp-

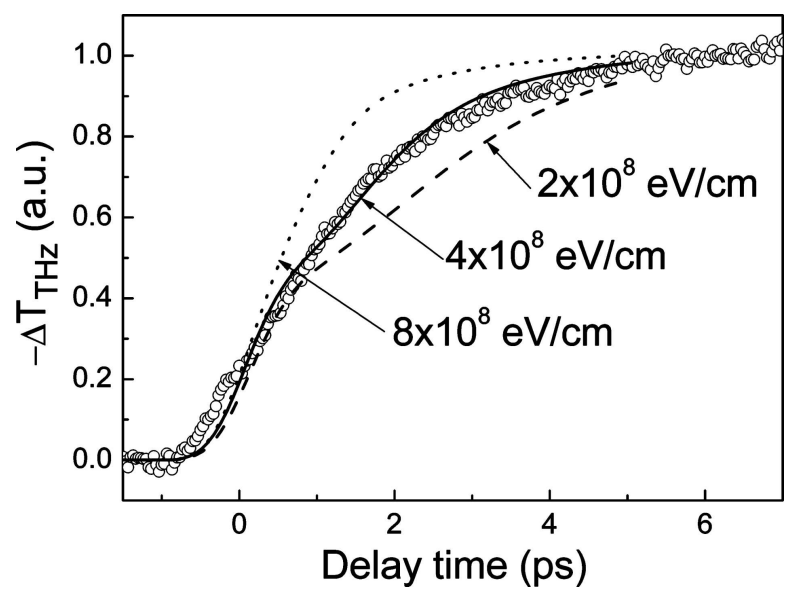

Fig. 2. Initial part of the time-resolved THz transmittance in $p$-type Ge sample (open circles). Dots, solid line, and dashed line: the Monte Carlo simulation with different coupling constant values.

tion induced by the photogenerated carriers decays at a fairly long time scale of several hundreds of picoseconds, which is most probably determined by the Auger or surface recombination processes. Most interesting is the initial part of transient, which is shown separately in Fig. 2. In contrast to the similar experiments performed on the majority of other semiconductors, the rising part of the transient is quite long; its duration ( $\sim 4 \mathrm{ps})$ is much longer than the temporal resolution of the experiment. Because the amplitude of the light-induced absorption at $\mathrm{THz}$ frequencies is proportional to the photoconductivity of the illuminated sample, this observation shows that the conductance of Ge reaches its stationary values at much longer time scale than the usual electron impulse relaxation times. This phenomenon can be explained as follows. Ti:sapphire laser quanta (of $1.55 \mathrm{eV}$ energy) excite the electrons into the central $\Gamma$ valley at the energies larger than the position of the subsidiary $\mathrm{L}$ and $\Delta$ minima, where the densities of states are much larger than in the $\Gamma$ minimum. Therefore, the majority of the electrons are scattered to the subsidiary conduction band valleys and only a small part $(\sim 0.5 \%)$ of them remain in the $\Gamma$ valley. Initial part of the induced $\mathrm{THz}$ absorption transient is caused by the L-electrons, which are $\sim 20$ times more mobile than the $\Delta$-valley electrons. A slower subsequent rise of the transient is caused by the cooling of the $\Delta$-electrons and their transfer to the higher mobility L-valleys.

These qualitative considerations are confirmed by the results of the Monte Carlo simulation presented in the same figure for comparison. An ensemble of 50000 macroparticles was used in the calculation; electron distributions were recalculated with a time step of $2 \mathrm{fs}$. The effective masses of electrons and holes, valley separations, the intra-valley and inter-valley deforma- 


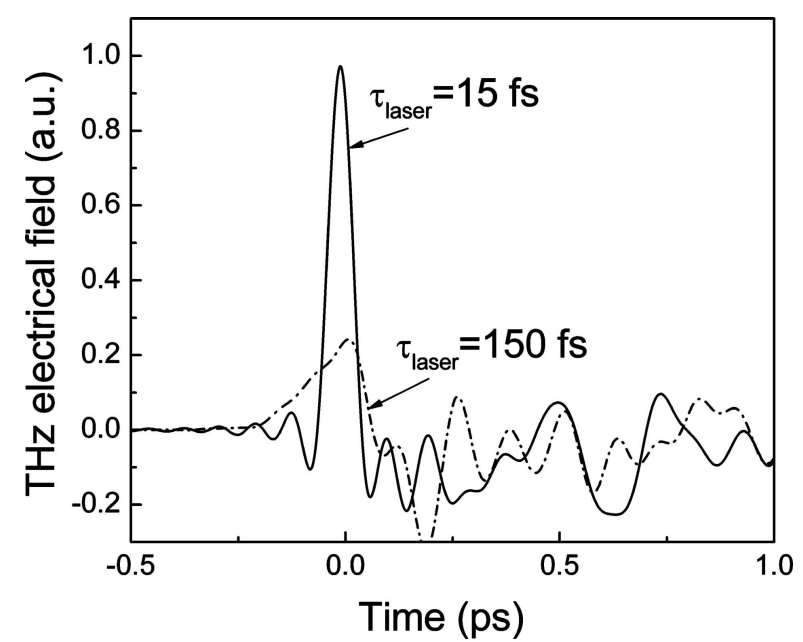

Fig. 3. Calculated temporal waveforms of the THz pulses emitted by the Ge surface excited by $150 \mathrm{fs}$ and $15 \mathrm{fs}$ duration laser pulses.

tion potentials, and the energy of the optical and intervalley phonons for Ge are taken from [8,9]. The optical absorption and reflection coefficients at the wavelength of $800 \mathrm{~nm}$ are chosen to be $5 \cdot 10^{4} \mathrm{~cm}^{-1}$ and 0.42 accordingly [9]. Calculated transients are convoluted with 500 fs long (full width at half maximum) probe pulses. Three values of the coupling with acoustic phonons constant $D_{\Delta \mathrm{L}}$ responsible for L- $\Delta$ intervalley scattering were used in the calculation; the best agreement between the theory and the experiment was achieved for $D_{\Delta \mathrm{L}}$ equal to $4 \cdot 10^{8} \mathrm{eV} / \mathrm{cm}$. It has to be pointed out that this value coincides with the coupling constant that was used in [8] for the description of the hot-electron negative differential mobility effect in germanium.

The laser pulse duration in our experiments was longer than $50 \mathrm{fs}$, at which the photoexcited electrons from $\Gamma$ valley are scattered to $L$ and $\Delta$ valleys; therefore the $\Gamma$ valley contribution to the electrical transport effects was expected to be rather weak. The situation could be completely different if shorter laser pulses were used for the excitation of Ge surfaces. In such a case, electron intervalley scattering could act as an additional photocurrent decay mechanism leading to extremely fast current transients. These transients could be successfully exploited in laser-activated dipole antennae for $\mathrm{THz}$ radiation generation and detection, as well as in wide-band surface emitters at $\mathrm{THz}$ frequencies. It is known, e.g., that Ge surfaces illuminated by $100 \mathrm{fs}$ and longer laser pulses are rather poor THz radiation emitters [10]. However, when exciting by much shorter laser pulses, one could make use of the very fast ballistic movement of electrons in the low effective mass $\Gamma$ valley and the enhancement of the photocurrent surge at the illuminated surfaces. Figure 3 compares simulated $\mathrm{THz}$ transients radiated by the Ge surfaces excited by 150 fs and 15 fs duration laser pulses. As it can be seen from this figure, the shortening of the pulse duration increases the $\mathrm{THz}$ transient amplitude by nearly one order of magnitude, making Ge comparable to the best surface emitter materials.

\section{Conclusion}

In conclusion, photoexcited electron inter-valley redistribution dynamics have been studied both experimentally and theoretically. It was found that these dynamics are determined by the electron redistribution between different conduction band valleys; one of the most important material parameters - electron coupling constant with $\Delta$-L intervalley phonons - was evaluated.

\section{Acknowledgement}

This work was supported by the EU Excellence Centre "SELITEC" (Project No. G5MA-CT-202-04047).

\section{References}

[1] F.W. Smith, H.Q. Le, V. Diaduk, M.A. Hollis, A.R. Calawa, S. Gupta, M. Frankel, D.R. Dykaar, G.A. Mourou, and T.Y. Hsiang, Appl. Phys. Lett. 54, 890 (1989).

[2] A. Krotkus, R. Viselga, K. Bertulis, V. Jasutis, S. Marcinkevicius, and U. Olin, Appl. Phys. Lett. 66, 1939 (1995).

[3] U. Siegner, R. Fluck, G. Zhang, and U. Keller, Appl. Phys. Lett. 69, 2566 (1996).

[4] B.B. Hu, E.A. De Suoza, W.M. Knox, J.E. Cunningham, M.C. Nuss, A.V. Kuznetsov, and S.L. Chuang, Phys. Rev. Lett. 74, 1689 (1995).

[5] S.S. Prabhu, S.E. Ralph, M.R. Melloch, and E.S. Harmon, Appl. Phys. Lett. 70, 2419 (1997).

[6] M.C. Beard, G.M. Turner, and C.A. Schmuttenmaer, J. Appl. Phys. 90, 5915 (2001).

[7] C. Jacoboni and L. Reggiani, Rev. Mod. Phys. 55, 645 (1983).

[8] W. Fawcett and E.G.S. Paige, J. Phys. C 4, 1801 (1971).

[9] A. Dargys and J. Kundrotas, Handbook on Physical Properties of Ge, Si, GaAs and InP (Science and Encyclopedia Publishers, Vilnius, 1994).

[10] X.C. Zhang, B.B. Hu, J.T. Darrow, and D.H. Auston, Appl. Phys. Lett. 56, 1011 (1990). 


\title{
ELEKTRONU TARPSLĖNINIO PERSISKIRSTYMO GERMANYJE TYRIMAS OPTINIO ŽADINIMO IR TERAHERCINIO STROBAVIMO METODU
}

\author{
A. Urbanowicz ${ }^{\text {a }}$, R. Adomavičius ${ }^{\text {a }}$, A. Krotkus ${ }^{\text {a }}$, V.L. Malevich ${ }^{\text {b }}$ \\ a Puslaidininkiu fizikos institutas, Vilnius, Lietuva \\ ${ }^{\mathrm{b}}$ Fizikos institutas, Baltarusijos nacionalinè mokslu akademija, Minskas, Baltarusija
}

\section{Santrauka}

Elektronų dinamika germanyje (Ge) studijuota eksperimentiškai ir teoriškai. Matomos šviesos žadinimo ir terahercinio zondavimo metodas naudotas eksperimentiniam elektronų dinamikos stebejjimui; tyrimo rezultatai palyginti su skaitmeniniu Monte Karlo modeliavimu. Iš eksperimentinių ir teorinių rezultatų palyginimo nustatyta elektronų sklaidos deformacijos potencialo vertè tarp neekvivalentinių L ir $\Delta$ lygmenų. Aptartas galimas Ge kristalų panaudojimas ultrasparčioje optoelektronikoje. 